\title{
Forecasting Future Asthma Hospital Encounters of Patients With Asthma in an Academic Health Care System: Predictive Model Development and Secondary Analysis Study
}

Yao Tong ${ }^{1}$, MSc; Amanda I Messinger ${ }^{2}$, MD; Adam B Wilcox ${ }^{1}$, DPhil; Sean D Mooney ${ }^{1}$, DPhil; Giana H Davidson ${ }^{3,4}$, MPH, MD; Pradeep Suri ${ }^{5,6,7}$, MD, MS; Gang Luo ${ }^{1}$, DPhil

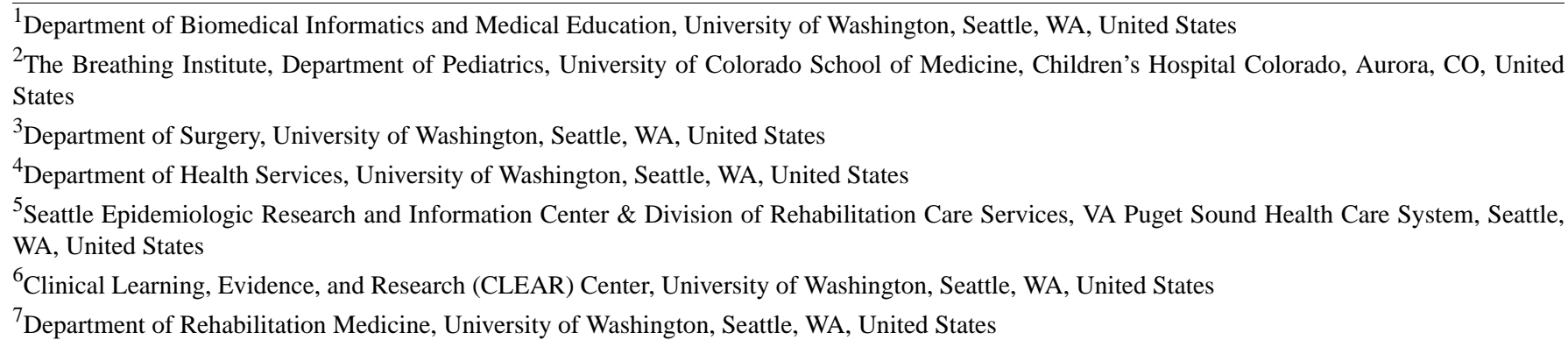

Corresponding Author:

Gang Luo, DPhil

Department of Biomedical Informatics and Medical Education

University of Washington

UW Medicine South Lake Union, 850 Republican Street, Building C, Box 358047

Seattle, WA, 98109

United States

Phone: 12062214596

Email: gangluo@cs.wisc.edu

\section{Abstract}

Background: Asthma affects a large proportion of the population and leads to many hospital encounters involving both hospitalizations and emergency department visits every year. To lower the number of such encounters, many health care systems and health plans deploy predictive models to prospectively identify patients at high risk and offer them care management services for preventive care. However, the previous models do not have sufficient accuracy for serving this purpose well. Embracing the modeling strategy of examining many candidate features, we built a new machine learning model to forecast future asthma hospital encounters of patients with asthma at Intermountain Healthcare, a nonacademic health care system. This model is more accurate than the previously published models. However, it is unclear how well our modeling strategy generalizes to academic health care systems, whose patient composition differs from that of Intermountain Healthcare.

Objective: This study aims to evaluate the generalizability of our modeling strategy to the University of Washington Medicine (UWM), an academic health care system.

Methods: All adult patients with asthma who visited UWM facilities between 2011 and 2018 served as the patient cohort. We considered 234 candidate features. Through a secondary analysis of 82,888 UWM data instances from 2011 to 2018, we built a machine learning model to forecast asthma hospital encounters of patients with asthma in the subsequent 12 months.

Results: Our UWM model yielded an area under the receiver operating characteristic curve (AUC) of 0.902 . When placing the cutoff point for making binary classification at the top $10 \%(1464 / 14,644)$ of patients with asthma with the largest forecasted risk, our UWM model yielded an accuracy of $90.6 \%$ (13,268/14,644), a sensitivity of 70.2\% (153/218), and a specificity of 90.91\% (13,115/14,426).

Conclusions: Our modeling strategy showed excellent generalizability to the UWM, leading to a model with an AUC that is higher than all of the AUCs previously reported in the literature for forecasting asthma hospital encounters. After further optimization, our model could be used to facilitate the efficient and effective allocation of asthma care management resources to improve outcomes. 
International Registered Report Identifier (IRRID): RR2-10.2196/resprot.5039

(J Med Internet Res 2021;23(4):e22796) doi: $10.2196 / 22796$

\section{KEYWORDS}

asthma; forecasting; machine learning; patient care management; risk factors

\section{Introduction}

\section{Background}

In the United States, $7.7 \%$ of people have asthma, which causes 188,968 hospitalizations, 1,776,851 emergency department (ED) visits, and 3441 deaths annually [1]. To reduce asthma hospital encounters covering both hospitalizations and ED visits, many health care systems and health plans deploy predictive models to prospectively find patients at high risk and offer them care management services for preventive care. The University of Washington Medicine (UWM), Intermountain Healthcare, and Kaiser Permanente Northern California [2] are 3 examples of such health care systems. Examples of such health plans include those in 9 of the 12 metropolitan communities [3]. Once a patient is deemed to be at high risk and enrolled in a care management program, a care manager will regularly assess the patient's asthma control, adjust the patient's asthma medications if necessary, and help the patient make appointments for health and related services. Using effective care management, as many as $40 \%$ of future hospital encounters by patients with asthma can be avoided [4-7].

Owing to its limited service capacity, a care management program normally enrolls at most $3 \%$ of patients with a particular condition [8]. To maximize the benefits of this resource-intensive program, it is crucial for the program to only enroll the patients who are at the highest risk. After all, the deployed predictive model's accuracy (or lack thereof) places an upper bound on the program's effectiveness. Several other research groups have built multiple models for forecasting future asthma hospital encounters of patients with asthma. Every model examined only a few features [2,9-22]. Overlooking some important features in the model degrades model accuracy, making the model miss at least half of the patients who will experience future asthma hospital encounters and incorrectly forecast future asthma hospital encounters for many other patients with asthma. These errors result in impaired patient outcomes and wasted health care spending [23]. In nonmedical fields, people frequently adopt the modeling strategy of examining many candidate features to enhance the accuracy of machine learning models [24-27]. Embracing this modeling strategy for medical data, we built a new machine learning model to forecast future asthma hospital encounters of patients with asthma at Intermountain Healthcare, a nonacademic health care system [23]. Our Intermountain Healthcare model raised the area under the receiver operating characteristic curve (AUC) to 0.859 , which is higher than that of every previously published model by 0.049 or more. Although this progress is encouraging, it is unclear how well our modeling strategy generalizes to academic health care systems, which normally care for more complex and sicker patients than nonacademic health care systems [28].

\section{Objective}

This study evaluates the generalizability of our modeling strategy to the UWM, an academic health care system. Similar to the Intermountain Healthcare model [23], our UWM model uses clinical and administrative data to forecast future asthma hospital encounters of patients with asthma covering both hospitalizations and ED visits. There are 2 possible values of the categorical dependent variable: whether the patient with asthma will experience asthma hospital encounters in the subsequent 12 months. This paper reports on the development and evaluation of the UWM model.

\section{Our Contributions}

This study makes the following 3 innovative contributions:

1. We conducted the first evaluation of the generalizability of our modeling strategy to an academic health care system.

2. We evaluated the predictive power of 71 new features, which were not used in our previous study [23], for forecasting asthma hospital encounters.

3. We evaluated the generalizability of our Intermountain Healthcare model to the UWM and the generalizability of our UWM model to Intermountain Healthcare. To the best of our knowledge, this is the first study to evaluate model generalizability in both directions. Previously, model generalizability was evaluated solely in one direction by assessing the performance of a model built using one site's data on another site's data [17].

\section{Methods}

\section{Study Design and Ethics Approval}

The institutional review boards of the UWM and Intermountain Healthcare approved this secondary analysis study on clinical and administrative data.

\section{Patient Cohort}

The UWM is the largest academic health care system in Washington State. Its enterprise data warehouse contains clinical and administrative data from 3 hospitals and 12 clinics for adults. Our patient cohort covered adult patients with asthma (age $\geq 18$ years) who visited any of these UWM facilities between 2011 and 2018. We defined a patient as having asthma in a specific year if the encounter billing database contained at least one asthma diagnosis code (International Classification of Diseases, Ninth Revision [ICD-9]: 493.0x, 493.1x, 493.8x, 493.9x; International Classification of Diseases, Tenth Revision [ICD-10]: J45.x) record of the patient in that year [10,29,30]. As the sole exclusion criterion, we eliminated patients who passed away in that year. 


\section{Prediction Target (Dependent Variable)}

The prediction target was from our previous study [23]. We defined an asthma hospital encounter as a hospitalization or an ED visit with asthma as its principal diagnosis (ICD-9: 493.0x, 493.1x, 493.8x, 493.9x; ICD-10: J45.x). As Figure 1 shows, for each patient deemed to have asthma in a specific year, we used any asthma hospital encounter at UWM in the subsequent 12 months, that is, the 12 months after the end of this year, as the outcome of interest. We adopted the patient's data by the end of this year to forecast the patient's outcome in the subsequent 12 months.

Figure 1. The time periods used to compute the features and prediction target for an index year and patient pair. PCP: primary care provider.

Time period that spans from 2011 to the index

year and was used to compute 27 features

Time period that spans the pre-index and index years and was used to compute one feature, the percentage of the PCP's asthmatic patients in the pre-index year incurring asthma hospital encounters in the index year

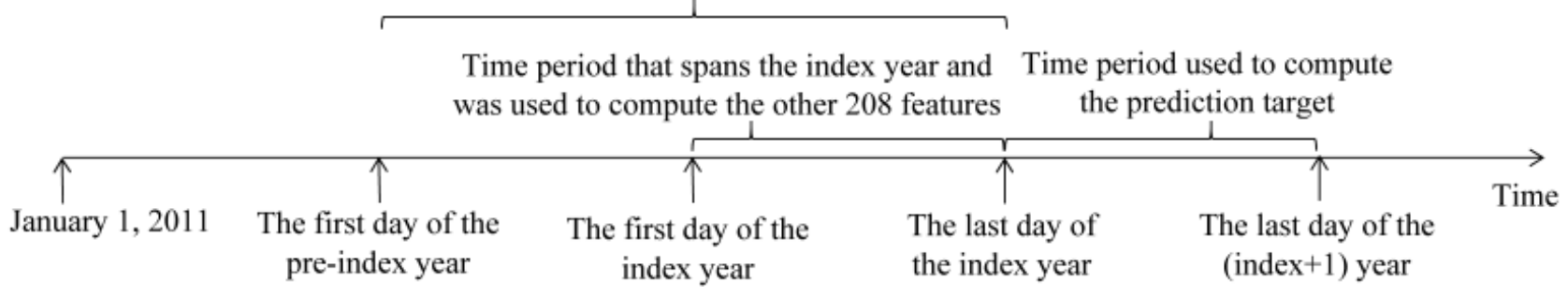

\section{Data Set}

The UWM enterprise data warehouse supplied a structured data set that contained clinical and administrative data on our patient cohort's encounters at the 3 UWM hospitals and 12 UWM clinics between 2011 and 2019.

\section{Features (Independent Variables)}

Similar to our previous study [23], we examined 234 candidate features describing a wide variety of characteristics. Table S1 of Multimedia Appendix 1 describes these features calculated on the structured attributes in our data set, with the 71 new features not used in our previous study [23] marked in italics. Throughout this paper, every mention of the number of a particular kind of items such as medications counts multiplicity whenever the word differing is absent. For instance, consider a patient who was ordered medications twice in a given year. The first time, medications 1 and 2 were ordered for the patient. The second time, medications 2 and 3 were ordered for the patient. Then, the total number of medications ordered for the patient in this year was 4 . The total number of differing medications ordered for the patient in this year was 3 .

Every input data instance to the predictive model addresses a unique index year and patient pair and is used to forecast the patient's outcome in the subsequent 12 months, that is, the 12 months after the end of the index year. For that pair, we computed the patient's age and primary care provider (PCP) on the last day of the index year. The PCP identified was the patient's last PCP recorded in the electronic medical record system on or before the last day of the index year. As Figure 1 shows, adopting the data in the preindex and index years, we computed 1 feature: the percentage of the PCP's patients with asthma in the preindex year incurring asthma hospital encounters in the index year. Using the data from 2011 to the index year, we computed 25 features: the number of years from the first encounter related to asthma in the data set, the number of years from the first encounter related to chronic obstructive pulmonary disease in the data set, family history of asthma, 15 features related to the problem list, and 7 allergy features. We derived the other 208 features from the data in the index year.

\section{Data Analysis}

\section{Data Preparation}

Our UWM data set included peak expiratory flow values, which were absent in the Intermountain Healthcare data set adopted in our previous study [23]. Adopting the lower and upper bounds supplied by a clinical expert in our team, we deemed all peak expiratory flow values more than 700 biologically implausible. Adopting the data preparation approach used in our previous paper [23] and this criterion, we pinpointed biologically implausible values, marked them missing, and normalized data. As the outcome of interest came from the subsequent year, our data set included 8 years of effective data (2011-2018) over the 9 -year period of 2011-2019. To be consistent with future model use in practice, we used the 2011-2017 data to train the models and the 2018 data to evaluate model performance.

\section{Performance Metrics}

As presented in Table 1 and the formulas below, we evaluated model performance using 6 standard metrics: accuracy, AUC, sensitivity, specificity, positive predictive value (PPV), and negative predictive value (NPV).

$$
\begin{aligned}
& \text { Accuracy }=(\mathrm{TP}+\mathrm{TN}) /(\mathrm{TP}+\mathrm{TN}+\mathrm{FP}+\mathrm{FN})(\mathbf{1}) \\
& \text { Sensitivity }=\mathrm{TP} /(\mathrm{TP}+\mathrm{FN})(\mathbf{2}) \\
& \text { Specificity }=\mathrm{TN} /(\mathrm{TN}+\mathrm{FP})(\mathbf{3}) \\
& \mathrm{PPV}=\mathrm{TP} /(\mathrm{TP}+\mathrm{FP})(\mathbf{4}) \\
& \mathrm{NPV}=\mathrm{TN} /(\mathrm{TN}+\mathrm{FN})(\mathbf{5})
\end{aligned}
$$

Here, TP stands for true positive. TN stands for true negative. FP stands for false positive. FN stands for false negative. 
Table 1. The confusion matrix.

\begin{tabular}{lll}
\hline Outcome class & Future asthma hospital encounters & No future asthma hospital encounter \\
\hline Forecasted future asthma hospital encounters & True positive & False positive \\
Forecasted no future asthma hospital encounter & False negative & True negative \\
\hline
\end{tabular}

We performed a 1000-fold bootstrap analysis [31] to calculate 95\% CIs for the 6 performance measures. For instance, we computed our final UWM model's performance measures for each bootstrap sample of the 2018 data. The 2.5 th and 97.5 th percentiles of the 1000 values we obtained for every performance metric gave the $95 \%$ CI of the corresponding performance measure. We rendered the receiver operating characteristic curve to show the sensitivity-specificity tradeoff.

\section{Classification Algorithms}

As in our previous paper [23], our predictive models were built using Waikato Environment for Knowledge Analysis (Weka) Version 3.9 [32]. Weka is a core open-source software package for data mining and machine learning. It integrates a large number of popular feature selection techniques and machine learning algorithms. We checked the extreme gradient boosting (XGBoost) machine learning classification algorithm [33] implemented in the software package XGBoost4J [34] and the 39 native classification algorithms in Weka listed in our previous paper's web-based multimedia appendix [23]. As an efficient and scalable realization of gradient boosting, XGBoost is a form of an ensemble of decision trees. As XGBoost accepts only numerical features, we used one-hot encoding to transform categorical features into numerical features before giving them to XGBoost. We used the 2011-2017 training data and the automatic machine learning model selection method developed in our previous work [35] to automatically select the feature selection technique, classification algorithm, data balancing method for handling imbalanced data, and hyperparameter values among all of the pertinent ones. On average, our method can reduce the model error rate by $11 \%$ and search time by 28 times compared with the modern Auto-WEKA automatic machine learning model selection method $[35,36]$.

This study mainly evaluated our modeling strategy's generalizability to the UWM by using the UWM training set to train multiple models and then checking their performance on the UWM test set. In addition, we conducted 2 experiments to evaluate the generalizability of our models across health systems.

\section{Evaluating the Generalizability of Our Intermountain Healthcare Model to the UWM}

In the first experiment, we evaluated the generalizability of our Intermountain Healthcare model to the UWM. Previously, we developed both a simplified model and a full model on the Intermountain Healthcare data set [23]. Our simplified Intermountain Healthcare model uses the top 21 features whose importance values calculated by XGBoost on that data set are $\geq 0.01$ [23]. Compared with our full Intermountain Healthcare model using 142 features, our simplified Intermountain Healthcare model retained nearly all of its predictive power. Our UWM data set contained the top 21 features and missed some other features adopted in our full Intermountain Healthcare model. We evaluated the performance of our simplified Intermountain Healthcare model on the UWM test set twice. The first time, we retrained our simplified Intermountain Healthcare model on the UWM training set. The second time, we did not perform retraining and directly applied our original simplified Intermountain Healthcare model trained on the Intermountain Healthcare training set.

\section{Evaluating the Generalizability of Our UWM Model to Intermountain Healthcare}

In the second experiment, we evaluated the generalizability of our UWM model to Intermountain Healthcare. We used a simplified UWM model, which used only the top features whose importance values calculated by XGBoost on the UWM training set were $\geq 0.01$. For any top feature that was newly introduced in this study and was not used in our previous study [23], we computed the feature on the Intermountain Healthcare data set. We evaluated our simplified UWM model's performance on the Intermountain Healthcare test set twice. The first time, we retrained our simplified UWM model using the Intermountain Healthcare training set. The second time, we did not perform retraining and directly applied our simplified UWM model trained on the UWM training set.

\section{Results}

\section{Demographic and Clinical Characteristics of Our Patient Cohort}

Each data instance addresses a unique index year and patient pair. Tables 2 and 3 show the demographic and clinical characteristics of our UWM patient cohort during 2011-2017 and 2018, respectively. The characteristics were similar across the 2 periods. During 2011-2017 and 2018, 1.74\% (1184/68,244) and $1.49 \%(218 / 14,644)$ of data instances were linked to asthma hospital encounters in the subsequent 12 months, respectively. 
Table 2. Demographic and clinical characteristics of patients with asthma at the University of Washington Medicine during 2011-2017.

\begin{tabular}{|c|c|c|c|}
\hline Characteristic & $\begin{array}{l}\text { Data instances } \\
(\mathrm{N}=68,244), \mathrm{n}(\%)\end{array}$ & $\begin{array}{l}\text { Data instances connecting to asthma } \\
\text { hospital encounters in the subsequent } 12 \\
\text { months }(\mathrm{n}=1184), \mathrm{n}(\%)\end{array}$ & $\begin{array}{l}\text { Data instances connecting to no asthma } \\
\text { hospital encounter in the subsequent } \\
12 \text { months }(\mathrm{n}=67,060), \mathrm{n}(\%)\end{array}$ \\
\hline \multicolumn{4}{|l|}{ Age (years) } \\
\hline$<40$ & $23,459(34.38)$ & $466(39.36)$ & $22,993(34.29)$ \\
\hline $40-65$ & $33,889(49.66)$ & $583(49.24)$ & $33,306(49.67)$ \\
\hline$>65$ & $10,896(15.97)$ & $135(11.40)$ & $10,761(16.05)$ \\
\hline \multicolumn{4}{|l|}{ Gender } \\
\hline Male & $24,198(35.46)$ & $551(46.54)$ & $23,647(35.26)$ \\
\hline Female & $44,046(64.54)$ & $633(53.46)$ & $43,413(64.74)$ \\
\hline \multicolumn{4}{|l|}{ Race } \\
\hline American Indian or Alaska native & $1358(1.99)$ & $32(2.70)$ & $1326(1.98)$ \\
\hline Asian & $5721(8.38)$ & $96(8.11)$ & $5625(8.39)$ \\
\hline Black or African American & $8420(12.34)$ & $520(43.92)$ & $7900(11.78)$ \\
\hline $\begin{array}{l}\text { Native Hawaiian or other Pacific is- } \\
\text { lander }\end{array}$ & $673(0.99)$ & $14(1.18)$ & $659(0.98)$ \\
\hline White & 47,747 (69.97) & $507(42.82)$ & $47,240(70.44)$ \\
\hline Unknown or not reported & $4325(6.34)$ & $15(1.27)$ & $4310(6.43)$ \\
\hline \multicolumn{4}{|l|}{ Ethnicity } \\
\hline Hispanic & $3526(5.17)$ & $82(6.93)$ & $3444(5.14)$ \\
\hline Non-Hispanic & $56,309(82.51)$ & $1062(89.70)$ & $55,247(82.38)$ \\
\hline Unknown or not reported & $8409(12.32)$ & $40(3.38)$ & $8369(12.48)$ \\
\hline \multicolumn{4}{|l|}{ Insurance } \\
\hline Private & $40,009(58.63)$ & $424(35.81)$ & $39,585(59.03)$ \\
\hline Public & $28,787(42.18)$ & $756(63.85)$ & $28,031(41.80)$ \\
\hline Self-paid or charity & $1366(2.00)$ & $65(5.49)$ & $1301(1.94)$ \\
\hline \multicolumn{4}{|c|}{ Number of years from the first encounter related to asthma in the data set } \\
\hline$\leq 3$ & $60,873(89.20)$ & $986(83.28)$ & $59,887(89.30)$ \\
\hline$>3$ & $7371(10.80)$ & $198(16.72)$ & $7173(10.70)$ \\
\hline \multicolumn{4}{|l|}{ Asthma medication prescription } \\
\hline Inhaled corticosteroid & $28,889(42.33)$ & $626(52.88)$ & $28,263(42.15)$ \\
\hline $\begin{array}{l}\text { Inhaled corticosteroid and long-acting } \\
\beta-2 \text { agonist combination }\end{array}$ & $22,015(32.26)$ & 499 (42.15) & $21,516(32.08)$ \\
\hline Leukotriene modifier & $8171(11.97)$ & $201(16.98)$ & $7970(11.88)$ \\
\hline Long-acting $\beta-2$ agonist & $12,293(18.01)$ & $374(31.59)$ & $11,919(17.77)$ \\
\hline Mast cell stabilizer & $47(0.07)$ & $4(0.34)$ & $43(0.06)$ \\
\hline Short-acting inhaled $\beta-2$ agonist & $47,808(70.05)$ & $1010(85.30)$ & $46,798(69.79)$ \\
\hline Systemic corticosteroid & $18,699(27.40)$ & $614(51.86)$ & 18,085 (26.97) \\
\hline \multicolumn{4}{|l|}{ Comorbidity } \\
\hline Allergic rhinitis & $11,449(16.78)$ & $172(14.53)$ & $11,277(16.82)$ \\
\hline Anxiety or depression & $19,885(29.14)$ & $372(31.42)$ & $19,513(29.10)$ \\
\hline Bronchopulmonary dysplasia & $1(0)$ & $0(0)$ & $1(0)$ \\
\hline Chronic obstructive pulmonary disease & $3826(5.61)$ & $133(11.23)$ & $3693(5.51)$ \\
\hline Cystic fibrosis & $61(0.09)$ & $1(0.08)$ & $60(0.09)$ \\
\hline
\end{tabular}




\begin{tabular}{|c|c|c|c|}
\hline Characteristic & $\begin{array}{l}\text { Data instances } \\
(\mathrm{N}=68,244), \mathrm{n}(\%)\end{array}$ & $\begin{array}{l}\text { Data instances connecting to asthma } \\
\text { hospital encounters in the subsequent } 12 \\
\text { months }(\mathrm{n}=1184), \mathrm{n}(\%)\end{array}$ & $\begin{array}{l}\text { Data instances connecting to no asthma } \\
\text { hospital encounter in the subsequent } \\
12 \text { months }(\mathrm{n}=67,060), \mathrm{n}(\%)\end{array}$ \\
\hline Eczema & $3891(5.70)$ & $66(5.57)$ & $3825(5.70)$ \\
\hline Gastroesophageal reflux & $12,291(18.01)$ & $238(20.10)$ & $12,053(17.97)$ \\
\hline Obesity & $7845(11.50)$ & $177(14.95)$ & $7668(11.43)$ \\
\hline Sinusitis & $7261(10.64)$ & $89(7.52)$ & $7172(10.69)$ \\
\hline Sleep apnea & $4556(6.68)$ & $88(7.43)$ & $4468(6.66)$ \\
\hline \multicolumn{4}{|l|}{ Smoking status } \\
\hline Current smoker & $14,081(20.63)$ & $255(21.54)$ & $13,826(20.62)$ \\
\hline Former smoker & $15,530(22.76)$ & $221(18.67)$ & $15,309(22.83)$ \\
\hline Never smoker or unknown & $38,633(56.61)$ & $708(59.80)$ & $37,925(56.55)$ \\
\hline
\end{tabular}


Table 3. Demographic and clinical characteristics of patients with asthma at the University of Washington Medicine in 2018.

\begin{tabular}{|c|c|c|c|}
\hline Characteristic & $\begin{array}{l}\text { Data instances } \\
(\mathrm{N}=14,644), \mathrm{n}(\%)\end{array}$ & $\begin{array}{l}\text { Data instances connecting to asthma } \\
\text { hospital encounters in the subsequent } 12 \\
\text { months }(n=218), n(\%)\end{array}$ & $\begin{array}{l}\text { Data instances connecting to no asthma } \\
\text { hospital encounter in the subsequent } 12 \\
\text { months }(n=14,426), \mathrm{n}(\%)\end{array}$ \\
\hline \multicolumn{4}{|l|}{ Age (years) } \\
\hline$<40$ & 4823 (32.9) & $77(35.3)$ & $4746(32.9)$ \\
\hline $40-65$ & $6794(46.4)$ & $111(50.9)$ & $6683(46.3)$ \\
\hline$>65$ & $3027(20.7)$ & $30(13.8)$ & $2997(20.8)$ \\
\hline \multicolumn{4}{|l|}{ Gender } \\
\hline Male & $5238(35.8)$ & $100(45.9)$ & $5138(35.6)$ \\
\hline Female & $9406(64.2)$ & $118(54.2)$ & $9288(64.4)$ \\
\hline \multicolumn{4}{|l|}{ Race } \\
\hline American Indian or Alaska native & $281(1.9)$ & $8(3.7)$ & $273(1.9)$ \\
\hline Asian & $1325(9.1)$ & $18(8.7)$ & $1307(9.1)$ \\
\hline Black or African American & $1570(10.7)$ & $79(36.2)$ & $1491(10.3)$ \\
\hline $\begin{array}{l}\text { Native Hawaiian or other Pacific } \\
\text { islander }\end{array}$ & $131(0.9)$ & $2(0.9)$ & $129(0.9)$ \\
\hline White & $10,213(69.7)$ & $110(50.5)$ & $10,103(70)$ \\
\hline Unknown or not reported & $1124(7.7)$ & $1(0.5)$ & $1123(7.8)$ \\
\hline \multicolumn{4}{|l|}{ Ethnicity } \\
\hline Hispanic & $850(5.8)$ & $20(9.2)$ & $830(5.7)$ \\
\hline Non-Hispanic & $12,566(85.8)$ & $196(89.9)$ & $12,370(85.7)$ \\
\hline Unknown or not reported & $1228(8.4)$ & $2(0.9)$ & $1226(8.5)$ \\
\hline \multicolumn{4}{|l|}{ Insurance } \\
\hline Private & $10,800(73.7)$ & $108(49.5)$ & $10,692(74.1)$ \\
\hline Public & $8023(54.8)$ & $182(83.5)$ & $7841(54.3)$ \\
\hline Self-paid or charity & $484(3.3)$ & $25(11.5)$ & $459(3.2)$ \\
\hline \multicolumn{4}{|c|}{ Number of years from the first encounter related to asthma in the data set } \\
\hline$\leq 3$ & $10,566(72.1)$ & $124(56.9)$ & $10,442(72.4)$ \\
\hline$>3$ & $4078(27.8)$ & $94(43.1)$ & $3984(27.6)$ \\
\hline \multicolumn{4}{|l|}{ Asthma medication prescription } \\
\hline Inhaled corticosteroid & $6177(42.2)$ & $108(49.5)$ & $6069(42.1)$ \\
\hline $\begin{array}{l}\text { Inhaled corticosteroid and long-act- } \\
\text { ing } \beta-2 \text { agonist combination }\end{array}$ & $4508(30.8)$ & $83(38.1)$ & $4425(30.7)$ \\
\hline Leukotriene modifier & $2176(14.9)$ & $46(21.1)$ & $2130(14.77)$ \\
\hline Long-acting $\beta$-2 agonist & $2518(17.2)$ & $62(28.4)$ & $2456(17.02)$ \\
\hline Mast cell stabilizer & $14(0.1)$ & $1(0.5)$ & $13(0.09)$ \\
\hline Short-acting inhaled $\beta-2$ agonist & $9704(66.3)$ & $164(75.2)$ & $9540(66.1)$ \\
\hline Systemic corticosteroid & $4163(28.4)$ & $120(55.1)$ & $4043(28)$ \\
\hline \multicolumn{4}{|l|}{ Comorbidity } \\
\hline Allergic rhinitis & 2095 (14.3) & $26(11.9)$ & $2069(14.3)$ \\
\hline Anxiety or depression & $4346(29.7)$ & $62(28.4)$ & $4284(29.7)$ \\
\hline Bronchopulmonary dysplasia & $4(0)$ & $0(0)$ & $4(0)$ \\
\hline $\begin{array}{l}\text { Chronic obstructive pulmonary dis- } \\
\text { ease }\end{array}$ & $932(6.4)$ & $30(13.8)$ & $902(6.2)$ \\
\hline Cystic fibrosis & $17(0.1)$ & $0(0)$ & $17(0.1)$ \\
\hline
\end{tabular}




\begin{tabular}{clll}
\hline Characteristic & $\begin{array}{l}\text { Data instances } \\
(\mathrm{N}=14,644), \mathrm{n}(\%)\end{array}$ & $\begin{array}{l}\text { Data instances connecting to asthma } \\
\text { hospital encounters in the subsequent 12 } \\
\text { months }(\mathrm{n}=218), \mathrm{n}(\%)\end{array}$ & $\begin{array}{l}\text { Data instances connecting to no asthma } \\
\text { hospital encounter in the subsequent 12 } \\
\text { months }(\mathrm{n}=14,426), \mathrm{n}(\%)\end{array}$ \\
\hline Eczema & $743(5.1)$ & $11(5.1)$ & $732(5.1)$ \\
Gastroesophageal reflux & $2657(18.1)$ & $46(21.1)$ & $2611(18.1)$ \\
Obesity & $1604(10.9)$ & $25(11.5)$ & $1579(10.9)$ \\
Sinusitis & $1372(9.4)$ & $15(6.9)$ & $1357(9.4)$ \\
$\quad$ Sleep apnea & $1499(10.2)$ & $24(11.0)$ & $1475(10.2)$ \\
Smoking status & & $49(22.5)$ & $3193(22.1)$ \\
Current smoker & $3242(22.1)$ & $41(18.8)$ & $3453(23.9)$ \\
Former smoker & $3494(23.9)$ & $128(58.7)$ & $7780(53.9)$ \\
Never smoker or unknown & $7908(54.0)$ & & \\
\hline
\end{tabular}

As the Chi-square 2-sample test showed, for both the 2011-2017 and 2018 data, the data instances connecting to future asthma hospital encounters and those connecting to no future asthma hospital encounter exhibited the same distribution for anxiety or depression occurrence $(P=.74$ for the 2018 data and $P=.09$ for the 2011-2017 data), bronchopulmonary dysplasia occurrence $(P=.99)$, cystic fibrosis occurrence $(P=.99)$, eczema occurrence $(P=.99$ for the 2018 data and $P=.90$ for the 2011-2017 data), gastroesophageal reflux occurrence $(P=.29$ for the 2018 data and $P=.06$ for the 2011-2017 data), and sleep apnea occurrence $(P=.79$ for the 2018 data and $P=.32$ for the 2011-2017 data). These 2 sets of data instances exhibited differing distributions for gender ( $P=.002$ for the 2018 data and $P<.001$ for the 2011-2017 data), ethnicity $(P<.001)$, insurance category $(P<.001)$, race $(P<.001)$, systemic corticosteroid prescription $(P<.001)$, inhaled corticosteroid prescription $(P=.02$ for the 2018 data and $P<.001$ for the 2011-2017 data), inhaled corticosteroid and long-acting $\beta-2$ agonist combination prescription $(P=.02$ for the 2018 data and $P<.001$ for the 2011-2017 data), short-acting inhaled $\beta$-2 agonist prescription ( $P=.006$ for the 2018 data and $P<.001$ for the 2011-2017 data), long-acting $\beta-2$ agonist prescription $(P<.001)$, leukotriene modifier prescription $(P=.01$ for the 2018 data and $P<.001$ for the 2011-2017 data), and chronic obstructive pulmonary disease occurrence $(P<.001)$. For the 2011-2017 data, these 2 sets of data instances exhibited differing distributions for mast cell stabilizer prescription $(P=.003)$, obesity occurrence $(P<.001)$, sinusitis occurrence $(P<.001)$, allergic rhinitis occurrence $(P=.04)$, and smoking status $(P=.003)$. For the 2018 data, these 2 sets of data instances exhibited the same distribution for mast cell stabilizer prescription $(P=.52)$, obesity occurrence $(P=.89)$, sinusitis occurrence $(P=.25)$, allergic rhinitis occurrence $(P=.36)$, and smoking status $(P=.19)$.

As the Cochran-Armitage trend test [37] showed, the data instances connecting to future asthma hospital encounters and those connecting to no future asthma hospital encounter exhibited the same distribution for age $(P=.06)$ in the 2018 data and differing distributions for age $(P<.001)$ in the 2011-2017 data. With regard to the 2018 and 2011-2017 data, these 2 sets of data instances exhibited differing distributions for the number of years from the first encounter related to asthma in the data set $(P<.001)$.

Table 4 shows the number of patients with asthma and their number of visits in each year between 2011 and 2018.

Table 4. The number of patients with asthma and their number of visits in each year between 2011 and 2018 .

\begin{tabular}{lll}
\hline Year & Number of patients with asthma & Number of visits by patients with asthma \\
\hline 2011 & 6852 & 32,910 \\
2012 & 7768 & 40,730 \\
2013 & 7754 & 39,385 \\
2014 & 9785 & 58,953 \\
2015 & 10,587 & 69,285 \\
2016 & 12,072 & 78,605 \\
2017 & 13,426 & 87,403 \\
2018 & 14,644 & 94,875 \\
\hline
\end{tabular}

\section{Classification Algorithm and Features Adopted by Our Final UWM Model}

Our automatic machine learning model selection method [35] selected the XGBoost classification algorithm [33]. XGBoost is a form of an ensemble of decision trees that can naturally deal with missing feature values. As described in Hastie et al [38] in detail, XGBoost automatically calculates the importance value of each feature based on its apportioned contribution to the model. Our final UWM model was formed using XGBoost 
and 71 features displayed in descending order of their importance values in Table S2 of Multimedia Appendix 1. XGBoost automatically removed the other features because they had no additional predictive power.

\section{Performance Measures Yielded by Our Final UWM Model}

On the UWM test set, our final model yielded an AUC of 0.902 (95\% CI 0.879-0.924). Figure 2 shows the receiver operating characteristic curve of the model. Table 5 lists the model's performance measures when the cutoff point for making binary classification was placed at different top percentages of patients with asthma with the largest forecasted risk. When the cutoff point was placed at the top $10 \%(1464 / 14,644)$, the model yielded an accuracy of $90.6 \%(13,268 / 14,644 ; 95 \%$ CI 90.13-91.06), a sensitivity of $70.2 \% \quad(153 / 218 ; 95 \%$ CI $63.8-76.0)$, a specificity of $90.91 \%(13,115 / 14,426 ; 95 \%$ CI 90.45-91.38), a PPV of $10.45 \%$ (153/1464; 95\% CI 8.90-11.97), and an NPV of $99.51 \%(13,115 / 13,180 ; 95 \%$ CI 99.39-99.62). Table 6 presents the confusion matrix of the model in this case.
Several features, such as a family history of asthma, were calculated on 2 or more years of data. When we dropped these features and checked solely those features calculated on 1 year of data, the AUC of the model decreased from 0.902 to 0.899 . If we used only the top 17 features in Table S2 of Multimedia Appendix 1 whose importance values are $\geq 0.01$ and ignored the other 217 features, the model's AUC decreased from 0.902 to 0.898 (95\% CI 0.874-0.919). In this case, when we placed the cutoff point for making binary classification at the top $10 \%$ $(1464 / 14,644)$ of patients with asthma with the largest forecasted risk, the model's accuracy decreased from $90.6 \%$ $(13,268 / 14,644)$ to $90.59 \% \quad(13,266 / 14,644 ; 95 \% \quad$ CI $90.11-91.06)$, sensitivity decreased from $70.2 \%(153 / 218)$ to $69.7 \%(152 / 218 ; 95 \%$ CI 63.6-75.5), specificity remained at $90.91 \%(13,114 / 14,426 ; 95 \%$ CI 90.42-91.37), PPV decreased from $10.45 \%(153 / 1464)$ to $10.38 \%(152 / 1464 ; 95 \%$ CI $8.82-11.97)$, and NPV decreased from $99.51 \%(13,115 / 13,180)$ to $99.5 \%(13,114 / 13,180 ; 95 \%$ CI $99.38-99.61)$.

Figure 2. The receiver operating characteristic curve of our final University of Washington Medicine model.

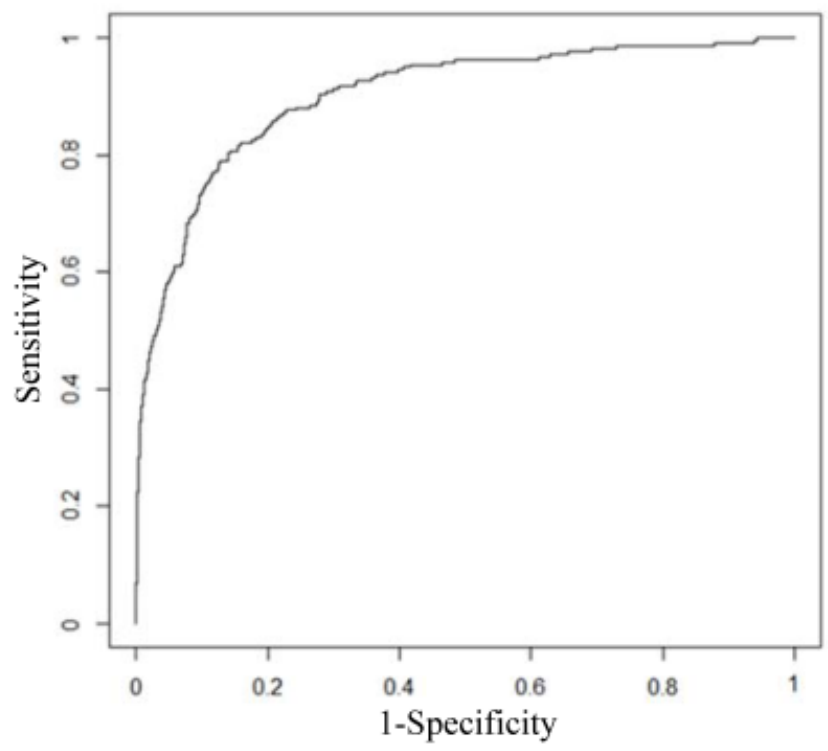


Table 5. Our final UWM model's performance measures when the cutoff point for making binary classification was placed at different top percentages of patients with asthma with the largest forecasted risk.

\begin{tabular}{|c|c|c|c|c|c|c|c|}
\hline \multirow{2}{*}{$\begin{array}{l}\text { Top percentage of pa- } \\
\text { tients with asthma with } \\
\text { the largest forecasted risk } \\
(\%)\end{array}$} & \multirow[t]{2}{*}{$\begin{array}{l}\text { Accuracy } \\
(\mathrm{N}=14,644), \mathrm{n}(\%)\end{array}$} & \multirow{2}{*}{$\begin{array}{l}\text { Sensitivity } \\
(\mathrm{N}=218), \mathrm{n} \\
(\%)\end{array}$} & \multirow[t]{2}{*}{$\begin{array}{l}\text { Specificity } \\
(\mathrm{N}=14,426), \mathrm{n}(\%)\end{array}$} & \multicolumn{2}{|l|}{$\mathrm{PPV}^{\mathrm{a}}$} & \multicolumn{2}{|l|}{$\mathrm{NPV}^{\mathrm{b}}$} \\
\hline & & & & $\mathrm{n}(\%)$ & $\mathrm{N}$ & $\mathrm{n}(\%)$ & $\mathrm{N}$ \\
\hline 1 & $14,410(98.4)$ & $65(29.8)$ & $14,345(99.4)$ & $65(44.5)$ & 146 & $14,345(98.9)$ & 14,498 \\
\hline 2 & $14,316(97.8)$ & $91(41.7)$ & 14,225 (98.6) & $91(31.2)$ & 292 & $14,225(99.1)$ & 14,352 \\
\hline 3 & $14,193(96.9)$ & $103(47.3)$ & $14,090(97.7)$ & $103(23.5)$ & 439 & $14,090(99.2)$ & 14,205 \\
\hline 4 & $14,061(96)$ & $110(50.5)$ & $13,951(96.7)$ & $110(18.8)$ & 585 & $13,951(99.2)$ & 14,059 \\
\hline 5 & $13,936(95.2)$ & $121(55.5)$ & $13,815(95.8)$ & $121(16.5)$ & 732 & $13,815(99.3)$ & 13,912 \\
\hline 6 & $13,806(94.3)$ & $129(59.2)$ & $13,677(94.8)$ & $129(14.7)$ & 878 & $13,677(99.3)$ & 13,766 \\
\hline 7 & $13,667(93.3)$ & $133(61)$ & $13,534(93.8)$ & $133(13)$ & 1025 & $13,534(99.4)$ & 13,619 \\
\hline 8 & $13,529(92.4)$ & 137 (62.8) & $13,392(92.8)$ & 137 (11.7) & 1171 & $13,392(99.4)$ & 13,473 \\
\hline 9 & 13,411 (91.6) & $151(69.3)$ & $13,260(91.9)$ & $151(11.5)$ & 1317 & $13,260(99.5)$ & 13,327 \\
\hline 10 & $13,268(90.6)$ & $153(70.2)$ & $13,115(90.9)$ & $153(10.5)$ & 1464 & 13,115 (99.5) & 13,180 \\
\hline 15 & $12,576(85.9)$ & $173(79.4)$ & $12,403(86)$ & $173(7.9)$ & 2196 & 12,403 (99.6) & 12,448 \\
\hline 20 & $11,860(81)$ & $181(83)$ & $11,679(81)$ & $181(6.2)$ & 2928 & $11,679(99.7)$ & 11,716 \\
\hline 25 & $11,147(76.1)$ & $191(87.6)$ & $10,956(75.9)$ & $191(5.2)$ & 3661 & $10,956(99.7)$ & 10,983 \\
\hline
\end{tabular}

${ }^{\mathrm{a} P P V}$ : positive predictive value.

${ }^{b} \mathrm{NPV}$ : negative predictive value.

Table 6. The confusion matrix of our final University of Washington Medicine model when the cutoff point for making binary classification was placed at the top $10 \%(1464 / 14,644)$ of patients with asthma with the largest forecasted risk.

\begin{tabular}{lll}
\hline Outcome class & Future asthma hospital encounter, $\mathrm{n}$ & No future asthma hospital encounter, $\mathrm{n}$ \\
\hline Forecasted future asthma hospital encounters & 153 & 1311 \\
Forecasted no future asthma hospital encounter & 65 & 13,115 \\
\hline
\end{tabular}

\section{Performance Measures Yielded by Our Simplified Intermountain Healthcare Model on UWM Data}

For our original simplified Intermountain Healthcare model trained on the Intermountain Healthcare training set [23], when we did not retrain the model and applied the model directly to the UWM test set, the model yielded an AUC of 0.861 (95\% CI 0.835-0.885). When we placed the cutoff point for making binary classification at the top $10 \%(1464 / 14,644)$ of patients with asthma with the largest forecasted risk, the model yielded an accuracy of $90.29 \%(13,222 / 14,644 ; 95 \%$ CI 89.81-90.77), a sensitivity of 59.6\% (130/218; 95\% CI 53.4-65.7), a specificity of $90.75 \%(13,092 / 14,426 ; 95 \%$ CI $90.28-91.20)$, a PPV of $8.88 \%(130 / 1464 ; 95 \%$ CI 7.46-10.34), and an NPV of $99.33 \%$ $(13,092 / 13,180 ; 95 \%$ CI 99.20-99.46).

After we used the UWM training set to retrain our simplified Intermountain Healthcare model [23], the retrained model yielded on the UWM test set an AUC of 0.874 (95\% CI 0.848-0.896). When we placed the cutoff point for making binary classification at the top $10 \%(1464 / 14,644)$ of patients with asthma with the largest forecasted risk, the model yielded an accuracy of $90.34 \%(13,230 / 14,644 ; 95 \%$ CI 89.85-90.80), a sensitivity of $61.5 \%(134 / 218 ; 95 \%$ CI 54.6-67.7), a specificity of $90.78 \%(13,096 / 14,426 ; 95 \%$ CI $90.32-91.23)$, a PPV of $9.15 \%(134 / 1464 ; 95 \%$ CI 7.62-10.66), and an NPV of $99.36 \%$ $(13,096 / 13,180 ; 95 \%$ CI 99.22-99.49).

\section{Performance Measures Yielded by Our Simplified UWM Model on Intermountain Healthcare Data}

Our simplified UWM model used only the top 17 features with importance values of $\geq 0.01$. For our simplified UWM model trained on the UWM training set, when we did not retrain the model and applied the model directly to the Intermountain Healthcare test set, the model yielded an AUC of 0.814 (95\% CI 0.798-0.830). When we placed the cutoff point for making binary classification at the top $10 \%(1926 / 19,256)$ of patients with asthma with the largest forecasted risk, the model yielded an accuracy of $89.76 \%(17,285 / 19,256 ; 95 \%$ CI 89.32-90.18), a sensitivity of $47.2 \%(383 / 812 ; 95 \%$ CI 43.8-50.6), a specificity of $91.64 \%(16,902 / 18,444 ; 95 \%$ CI 91.24-92.03), a PPV of $19.90 \%(383 / 1925 ; 95 \%$ CI 18.16-21.60), and an NPV of $97.52 \%(16,902 / 17,331 ; 95 \%$ CI 97.28-97.75).

After we used the Intermountain Healthcare training set to retrain our simplified UWM model, the retrained model yielded on the Intermountain Healthcare test set an AUC of $0.846(95 \%$ CI 0.831-0.859). When we placed the cutoff point for making 
binary classification at the top $10 \%(1926 / 19,256)$ of patients with asthma with the largest forecasted risk, the model yielded an accuracy of $90.11 \%(17,351 / 19,256$; $95 \%$ CI 89.64-90.56), a sensitivity of $51.2 \%(416 / 812 ; 95 \%$ CI 47.6-54.5), a specificity of $91.82 \%(16,935 / 18,444 ; 95 \%$ CI $91.43-92.21)$, a PPV of $21.62 \%(416 / 1,925 ; 95 \%$ CI 19.81-23.41), and an NPV of $97.72 \%(16,935 / 17,331 ; 95 \%$ CI 97.48-97.93).

\section{Discussion}

\section{Principal Findings}

We built a model on UWM data to forecast asthma hospital encounters of patients with asthma in the subsequent 12 months. Table 7 reveals that our final UWM model yielded an AUC that was higher than the previously reported AUC of every existing model [2,9-23], that is, our modeling strategy of examining many candidate features to enhance model accuracy showed excellent generalizability to the UWM. After further optimization to boost its accuracy and automatically provide explanations of its predictions $[39,40]$ to allow clinical interpretability, our UWM model could be used to facilitate efficient and effective allocation of asthma care management resources to improve outcomes.

In Table S2 of Multimedia Appendix 1, both the 5 most important features and multiple other features within the top 17 indicate a loss of asthma control. It is important to note that the loss of asthma control could be partly because of factors not well captured in our data, such as socioeconomic circumstances, variable management practices among providers, access to subspecialty clinicians, and nonadherence to medications and treatments. Variable asthma severity across patients over time also influences this process.

We checked 234 candidate features. Our final UWM model used $30.3 \%$ (71/234) of them. Despite being correlated with the outcome, many unused features had no extra predictive power on the UWM data set over the features adopted in our final UWM model.

For our original simplified Intermountain Healthcare model trained on the Intermountain Healthcare training set [23], when we did not retrain the model on the UWM data and directly applied the model, the model yielded an AUC of 0.861 on the UWM test set. This AUC is 0.041 lower than our final UWM model's AUC, but is still larger than the previously reported AUC of every existing model for forecasting future hospitalizations and ED visits of patients with asthma (Table 7). Therefore, our simplified Intermountain Healthcare model showed excellent generalizability to the UWM.

Compared with our full UWM model using 71 features, our simplified UWM model retained nearly all of its predictive power. For our simplified UWM model trained on the UWM training set, when we did not retrain the model on the Intermountain Healthcare data and directly applied the model, the model yielded an AUC of 0.814 on the Intermountain Healthcare test set. This AUC is 0.045 lower than our full Intermountain Healthcare model's AUC but is still larger than the previously reported AUC of every existing model developed by others for forecasting future hospitalizations and ED visits of patients with asthma (Table 7). Therefore, our simplified UWM model shows excellent generalizability to Intermountain Healthcare. 
Table 7. A comparison of our final University of Washington Medicine model and several existing models for forecasting future hospitalizations and emergency department (ED) visits of patients with asthma.

\begin{tabular}{|c|c|c|c|c|c|c|c|c|c|}
\hline Model & Prediction target & $\begin{array}{l}\text { Number of } \\
\text { data in- } \\
\text { stances }\end{array}$ & $\begin{array}{l}\text { Number of } \\
\text { features the } \\
\text { model adopted }\end{array}$ & $\begin{array}{l}\text { Classification al- } \\
\text { gorithm }\end{array}$ & $\begin{array}{l}\text { Sensitivity } \\
(\%)\end{array}$ & $\begin{array}{l}\text { Specificity } \\
(\%)\end{array}$ & $\begin{array}{l}\mathrm{PPV}^{\mathrm{a}} \\
(\%)\end{array}$ & $\begin{array}{l}\mathrm{NPV}^{\mathrm{b}} \\
(\%)\end{array}$ & $\mathrm{AUC}^{\mathrm{c}}$ \\
\hline $\begin{array}{l}\text { Our final UWM } \\
\text { model }\end{array}$ & $\begin{array}{l}\text { Asthma hospital } \\
\text { encounters }\end{array}$ & 82,888 & 71 & XGBoost $^{\mathrm{d}}$ & 70.2 & 90.91 & 10.45 & 99.51 & 0.902 \\
\hline $\begin{array}{l}\text { Our Intermountain } \\
\text { Healthcare model } \\
{[23]}\end{array}$ & $\begin{array}{l}\text { Asthma hospital } \\
\text { encounters }\end{array}$ & 334,564 & 142 & XGBoost & 53.69 & 91.93 & 22.65 & 97.83 & 0.859 \\
\hline Loymans et al [9] & $\begin{array}{l}\text { Asthma exacerba- } \\
\text { tion }\end{array}$ & 611 & 7 & $\begin{array}{l}\text { Logistic regres- } \\
\text { sion }\end{array}$ & $-^{\mathrm{e}}$ & - & - & - & 0.8 \\
\hline Schatz et al [10] & $\begin{array}{l}\text { Asthma-induced } \\
\text { hospitalization in } \\
\text { children }\end{array}$ & 4197 & 5 & $\begin{array}{l}\text { Logistic regres- } \\
\text { sion }\end{array}$ & 43.9 & 89.8 & 5.6 & 99.1 & 0.781 \\
\hline Schatz et al [10] & $\begin{array}{l}\text { Asthma-induced } \\
\text { hospitalization in } \\
\text { adults }\end{array}$ & 6904 & 3 & $\begin{array}{l}\text { Logistic regres- } \\
\text { sion }\end{array}$ & 44.9 & 87 & 3.9 & 99.3 & 0.712 \\
\hline Eisner et al [11] & $\begin{array}{l}\text { Asthma-induced } \\
\text { hospitalization }\end{array}$ & 2858 & 1 & $\begin{array}{l}\text { Logistic regres- } \\
\text { sion }\end{array}$ & - & - & - & - & 0.689 \\
\hline Eisner et al [11] & $\begin{array}{l}\text { Asthma-induced } \\
\text { ED visit }\end{array}$ & 2415 & 3 & $\begin{array}{l}\text { Logistic regres- } \\
\text { sion }\end{array}$ & - & - & - & - & 0.751 \\
\hline Sato et al [12] & $\begin{array}{l}\text { Severe asthma ex- } \\
\text { acerbation }\end{array}$ & 78 & 3 & $\begin{array}{l}\text { Classification and } \\
\text { regression tree }\end{array}$ & - & - & - & - & 0.625 \\
\hline Miller et al [14] & $\begin{array}{l}\text { Asthma hospital } \\
\text { encounters }\end{array}$ & 2821 & 17 & $\begin{array}{l}\text { Logistic regres- } \\
\text { sion }\end{array}$ & - & - & - & - & 0.81 \\
\hline Yurk et al [16] & $\begin{array}{l}\text { Lost day or hospi- } \\
\text { tal encounters for } \\
\text { asthma }\end{array}$ & 4888 & 11 & $\begin{array}{l}\text { Logistic regres- } \\
\text { sion }\end{array}$ & 77 & 63 & 82 & 56 & 0.78 \\
\hline Lieu et al [2] & $\begin{array}{l}\text { Asthma-induced } \\
\text { hospitalization }\end{array}$ & 16,520 & 7 & $\begin{array}{l}\text { Proportional-haz- } \\
\text { ards regression }\end{array}$ & - & - & - & - & 0.79 \\
\hline Lieu et al [2] & $\begin{array}{l}\text { Asthma-induced } \\
\text { ED visit }\end{array}$ & 16,520 & 7 & $\begin{array}{l}\text { Proportional-haz- } \\
\text { ards regression }\end{array}$ & - & - & - & - & 0.69 \\
\hline Lieu et al [18] & $\begin{array}{l}\text { Asthma hospital } \\
\text { encounters }\end{array}$ & 7141 & 4 & $\begin{array}{l}\text { Classification and } \\
\text { regression tree }\end{array}$ & 49 & 83.6 & 18.5 & - & - \\
\hline Schatz et al [19] & $\begin{array}{l}\text { Asthma hospital } \\
\text { encounters }\end{array}$ & 14,893 & 4 & $\begin{array}{l}\text { Logistic regres- } \\
\text { sion }\end{array}$ & 25.4 & 92 & 22 & 93.2 & 0.614 \\
\hline Forno et al [21] & $\begin{array}{l}\text { Severe asthma ex- } \\
\text { acerbation }\end{array}$ & 615 & 17 & Scoring & - & - & - & - & 0.75 \\
\hline Xiang et al [22] & $\begin{array}{l}\text { Asthma exacerba- } \\
\text { tion }\end{array}$ & 31,433 & - & $\begin{array}{l}\text { Recurrent neural } \\
\text { network }\end{array}$ & - & - & - & - & 0.70 \\
\hline
\end{tabular}

${ }^{\text {a}} \mathrm{PPV}$ : positive predictive value.

${ }^{\mathrm{b}} \mathrm{NPV}$ : negative predictive value.

${ }^{\mathrm{c}}$ AUC: area under the receiver operating characteristic curve.

${ }^{\mathrm{d}}$ XGBoost: extreme gradient boosting.

${ }^{\mathrm{e}}$ The initial paper showing the model did not give the performance measure.

\section{Comparison With the Previous Work}

Researchers have built multiple models to forecast future hospitalizations and ED visits of patients with asthma [2,9-23]. Table 7 compares our final UWM model with these models, which cover all the relevant models described in the systematic review by Loymans et al [17]. The final UWM model's AUC was 0.902 . The AUC of our Intermountain Healthcare model was 0.859 . All other existing models have a previously reported
AUC 0.81 [2,9-22], which is lower than our final UWM model's AUC by at least 0.091 .

It is important to consider the prevalence of the outcome of interest when comparing the performance of different predictive models. Compared with other existing models, the model by Yurk et al [16] achieved a higher sensitivity and PPV mainly because it adopted a different prediction target: asthma hospital encounters or at least 1 day lost for diminished activities or 
missing work for asthma. This prediction target had a 54\% prevalence rate in patients with asthma and was therefore easier to forecast. If the model by Yurk et al [16] were used to forecast asthma hospital encounters, an outcome that had a $<2 \%$ prevalence rate in patients with asthma, the model's sensitivity and PPV would likely drop.

The recurrent neural network model by Xiang et al [22] reached a low AUC of 0.7 , mainly because it used mostly inpatient data with little outpatient data; adopted only 3 types of attributes: medication, diagnosis, and demographics; and did not merge individual asthma medications into asthma medication categories such as nebulizers and short-acting $\beta-2$ agonists, that is, the low AUC does not prove that the recurrent neural network is ineffective at predicting asthma outcomes, but is mainly because of incomplete data and insufficient feature modeling. In comparison, to build our final UWM model, we used both inpatient and outpatient data, adopted many types of attributes, and merged individual asthma medications into asthma medication categories to better capture and model the relationship among different asthma medications.

Excluding the model by Yurk et al [16], every existing published model has a sensitivity $53.69 \%$, which is significantly lower than our final UWM model's sensitivity of $70.2 \%$. For patients with asthma who will have future asthma hospital encounters, sensitivity is the percentage of them identified by the model. The difference in sensitivity can have a significant impact on health care use. Owing to the high prevalence rate of asthma, for every $10 \%$ increase in the identified percentage of patients with asthma who would have future asthma hospital encounters, up to 7759 more hospitalizations and 71,074 more ED visits could be avoided in the United States each year with effective care management [1,4-7].

The prevalence rate of targeted poor outcomes greatly impacts the PPV of any predictive model [41]. In our UWM test data set, $1.49 \%(218 / 14,644)$ of patients with asthma had future asthma hospital encounters. When we placed the cutoff point for making binary classification at the top $10 \%(1464 / 14,644)$ of patients with asthma with the largest forecasted risk, an impeccable model in theory would yield the highest possible PPV of $14.89 \%$ (218/1464). Our final UWM model yielded a PPV of $10.45 \%(153 / 1464)$, which is $70.18 \%$ of the highest possible PPV in theory. In comparison, our Intermountain Healthcare model achieved a PPV of $22.65 \%$ [23]. This is $53.69 \%$ of the highest possible PPV that an impeccable model in theory would yield on the Intermountain Healthcare test set. The model by Lieu et al [18] yielded a PPV of $18.5 \%$ on a data set where $6.9 \%$ of patients with asthma had future asthma hospital encounters. The model by Schatz et al [19] yielded a PPV of $22 \%$ on a data set where $6.5 \%$ of patients with asthma had future asthma hospital encounters. Compared with our case with UWM, both populations have a higher prevalence of asthma hospital encounters, which allows the PPV to be higher. Excluding these PPVs and the PPV by the Yurk et al [16] model, no other existing published model's PPV exceeds 5.6\%.

Our final UWM model and our Intermountain Healthcare model [23] have similar top features with importance values of $\geq 0.01$. In both models, many top features are related to previous ED visits and asthma medications. We did not identify several candidate features at the time of constructing our Intermountain Healthcare model. They appeared as top features and affected the ranks and importance values of the other top features in our final UWM model.

Differing models in Table 7 were built using different patient cohorts and used similar but not necessarily identical prediction targets. Some features used in the models built by other researchers, such as certain features computed from patient-reported outcomes and patient surveys, are unavailable in our UWM data set. Therefore, we were unable to show the performance measures that the models built by other researchers would achieve on our UWM data set. However, we are confident that the techniques used in this study improved prediction accuracy. Our final UWM model was built using a state-of-the-art machine learning algorithm, XGBoost. Compared with statistical methods such as logistic regression, machine learning can enhance prediction accuracy with less strict assumptions on data distribution $[8,42,43]$. Compared with the models built by other researchers, our final UWM model was built using more patients and a more extensive set of candidate features constructed with careful feature engineering, both of which are known to often help improve prediction accuracy [24-27,32]. As partial evidence for this, we built predictive models for asthma hospital encounters using data from 3 health care systems: UWM, Intermountain Healthcare [23], and Kaiser Permanente Southern California [44]. For each of the 3 health care systems, we started model building with approximately 20 candidate features and obtained unsatisfactory accuracy. This motivated us to examine several hundred candidate features. Ultimately, for each of the 3 health care systems, we built a model with an AUC that is higher than all of the AUCs other researchers previously reported in the literature for forecasting asthma hospital encounters [23,44]. This demonstrates the generalizability of our modeling strategy for forecasting asthma hospital encounters.

\section{Considerations Concerning the Potential Clinical Use}

Our final UWM model has an AUC that is higher than all of the AUCs previously reported in the literature for forecasting asthma hospital encounters, but still had a seemingly low PPV of $10.4 \%$ (153/1464). Nevertheless, this model could be valuable in clinical care. First, health care systems such as UWM, Intermountain Healthcare, and Kaiser Permanente Northern California [2] use proprietary models to allocate asthma care management resources. These models and the models that were formerly built by others have similar performance measures. Our final UWM model has an AUC that is higher than the previously reported AUCs of all these models.

Second, as explained earlier, even an impeccable model in theory would reach a low PPV because the poor outcome of interest has a low prevalence rate in our data set. For such an outcome, sensitivity better reflects the model's potential clinical value than PPV. Our final UWM model had a higher sensitivity than the previously reported sensitivity of every existing model using a comparable prediction target. It is important to note that while asthma hospital encounters have an overall low prevalence rate in the population of patients with asthma, they have 
significant financial and clinical impacts at both the population and individual patient levels.

Third, a PPV of $10.45 \%$ (153/1464) is useful for identifying high-risk patients with asthma to receive low-cost preventive interventions. The following are 4 examples of such interventions: training the patient to record a diary about environmental triggers, coaching the patient to use an asthma inhaler correctly, coaching the patient to use a peak flow meter correctly and giving it to the patient to self-monitor symptoms at home, and asking a nurse to do extra follow-up phone calls with the patient or the patient's caregiver. These interventions could have a significant impact on patient outcomes.

The final UWM model used 71 features. Reducing the number of features could ease the clinical deployment of our model. To this end, if a minor decrease in prediction accuracy could be tolerated, one could adopt the top few features whose importance values are greater than a given threshold, such as 0.01 , and drop the other features. The importance value of a feature varies across health care systems. Ideally, the importance values of the features should first be calculated on a data set from the target health care system before choosing the features to retain.

As is typical with complex machine learning models, an XGBoost model using many features is difficult to interpret. This can limit clinical understandability and adoption, particularly by clinicians who are resistant to using automated tools. In the future, we plan to adopt our previously developed method $[39,40]$ to automatically explain the prediction results of our final UWM model.

The final UWM model was constructed using XGBoost [33]. For binary classification of imbalanced data, XGBoost leverages a hyperparameter, scale_pos_weight, to balance the weights of the 2 outcome classes [45]. To maximize the AUC of our UWM model, our automatic model selection method [35] altered scale_pos_weight to a nondefault value to balance the 2 outcome classes [46]. This incurs a side effect of significantly shrinking the model's forecasted probabilities of having future asthma hospital encounters to values much less than the actual probabilities [46]. This does not preclude us from choosing the top few percent of patients with asthma with the greatest forecasted risk to receive various preventive interventions. To prevent this side effect from occurring, we could retain scale_pos_weight at its default value of 1 without doing any balancing. As a tradeoff, the AUC of the model would decrease from 0.902 to 0.885 (95\% CI 0.861-0.907); however, this decreased AUC is still larger than all of the AUCs previously reported in the literature for forecasting asthma hospital encounters.

\section{Limitations}

This study has at least 4 limitations that could be interesting topics for future work, as follows:

1. It is possible to further increase the model accuracy by using features other than those checked in this study. For example, features derived from environmental and physiological data gathered by intelligent wearable devices can have this potential.

2. This study used purely structured data and checked only nondeep learning classification algorithms. It is possible to further increase the model accuracy by using deep learning as well as features derived from unstructured clinical notes using natural language processing techniques [40,47].

3. Our UWM data set contained no data on patients' health care use outside of UWM. Therefore, we limited the prediction target to asthma hospital encounters at UWM instead of asthma hospital encounters anywhere. In addition, the features we checked were derived from patients' incomplete administrative and clinical data [48-51]. It would be worth investigating how model accuracy would vary if we have more complete administrative and clinical data of patients [52].

4. This study evaluated the generalizability of our modeling strategy to an academic health care system on a single outcome of a complex chronic disease. We recently showed that our modeling strategy also generalizes well to Kaiser Permanente Southern California for the same predictive modeling problem [44]. We plan to investigate our modeling strategy's generalizability to other diseases, outcomes, and health care systems in the future.

\section{Conclusions}

In the first evaluation of its generalizability to an academic health care system, our modeling strategy of examining many candidate features to enhance prediction accuracy showed excellent generalizability to the UWM and led to a model with an AUC that is higher than all of the AUCs previously reported in the literature for forecasting asthma hospital encounters. After further optimization, our UWM model could be used to facilitate the efficient and effective allocation of asthma care management resources to improve outcomes.

\section{Acknowledgments}

The authors would like to thank Katy Atwood for helping with the retrieval of the UWM data set and Michael D Johnson for useful discussions. GL, SM, and GD were partially supported by the National Heart, Lung, and Blood Institute of the National Institutes of Health under award R01HL142503. The funders had no role in the study design, data collection and analysis, decision to publish, or preparation of the manuscript. YT did the work at the University of Washington when she was a visiting PhD student. 


\section{Authors' Contributions}

YT participated in data analysis and the writing of the first draft of the paper. GL conceptualized and designed the study, performed a literature review, participated in data analysis, and rewrote the whole paper. AM, AW, SM, GD, and PS provided feedback on various medical issues, contributed to conceptualizing the presentation, and revised the paper.

\section{Conflicts of Interest}

None declared.

\section{Multimedia Appendix 1}

The list of candidate features considered in this study.

[PDF File (Adobe PDF File), 105 KB-Multimedia Appendix 1]

\section{References}

1. Most recent national asthma data. Centers for Disease Control and Prevention. 2020. URL: https://www.cdc.gov/asthma/ most recent national asthma data.htm [accessed 2021-03-26]

2. Lieu TA, Quesenberry CP, Sorel ME, Mendoza GR, Leong AB. Computer-based models to identify high-risk children with asthma. Am J Respir Crit Care Med 1998 Apr;157(4 Pt 1):1173-1180. [doi: 10.1164/ajrccm.157.4.9708124] [Medline: 9563736]

3. Mays GP, Claxton G, White J. Managed care rebound? Recent changes in health plans' cost containment strategies. Health Aff (Millwood) 2004;Suppl Web Exclusives:427-436. [doi: 10.1377/hlthaff.w4.427] [Medline: 15451964]

4. Caloyeras JP, Liu H, Exum E, Broderick M, Mattke S. Managing manifest diseases, but not health risks, saved PepsiCo money over seven years. Health Aff (Millwood) 2014 Jan;33(1):124-131. [doi: 10.1377/hlthaff.2013.0625] [Medline: 24395944]

5. Greineder DK, Loane KC, Parks P. A randomized controlled trial of a pediatric asthma outreach program. J Allergy Clin Immunol 1999 Mar;103(3 Pt 1):436-440. [doi: 10.1016/s0091-6749(99)70468-9] [Medline: 10069877]

6. Kelly CS, Morrow AL, Shults J, Nakas N, Strope GL, Adelman RD. Outcomes evaluation of a comprehensive intervention program for asthmatic children enrolled in Medicaid. Pediatrics 2000 May;105(5):1029-1035. [doi: 10.1542/peds.105.5.1029] [Medline: 10790458 ]

7. Axelrod RC, Zimbro KS, Chetney RR, Sabol J, Ainsworth VJ. A disease management program utilising life coaches for children with asthma. J Clin Outcomes Manag 2001;8(6):38-42.

8. Axelrod RC, Vogel D. Predictive modeling in health plans. Dis Manag Health Outcomes 2003;11(12):779-787. [doi: 10.2165/00115677-200311120-00003]

9. Loymans RJ, Honkoop PJ, Termeer EH, Snoeck-Stroband JB, Assendelft WJ, Schermer TR, et al. Identifying patients at risk for severe exacerbations of asthma: development and external validation of a multivariable prediction model. Thorax 2016 Sep;71(9):838-846. [doi: 10.1136/thoraxjnl-2015-208138] [Medline: 27044486]

10. Schatz M, Cook EF, Joshua A, Petitti D. Risk factors for asthma hospitalizations in a managed care organization: development of a clinical prediction rule. Am J Manag Care 2003 Aug;9(8):538-547 [FREE Full text] [Medline: 12921231]

11. Eisner MD, Yegin A, Trzaskoma B. Severity of asthma score predicts clinical outcomes in patients with moderate to severe persistent asthma. Chest 2012 Jan;141(1):58-65. [doi: 10.1378/chest.11-0020] [Medline: 21885725]

12. Sato R, Tomita K, Sano H, Ichihashi H, Yamagata S, Sano A, et al. The strategy for predicting future exacerbation of asthma using a combination of the Asthma Control Test and lung function test. J Asthma 2009 Sep;46(7):677-682. [doi: 10.1080/02770900902972160] [Medline: 19728204]

13. Osborne ML, Pedula KL, O'Hollaren M, Ettinger KM, Stibolt T, Buist AS, et al. Assessing future need for acute care in adult asthmatics: the Profile of Asthma Risk Study: a prospective health maintenance organization-based study. Chest 2007 Oct;132(4):1151-1161. [doi: 10.1378/chest.05-3084] [Medline: 17573515 ]

14. Miller MK, Lee JH, Blanc PD, Pasta DJ, Gujrathi S, Barron H, TENOR Study Group. TENOR risk score predicts healthcare in adults with severe or difficult-to-treat asthma. Eur Respir J 2006 Dec;28(6):1145-1155 [FREE Full text] [doi: 10.1183/09031936.06.00145105] [Medline: $\underline{16870656}$ ]

15. Peters D, Chen C, Markson LE, Allen-Ramey FC, Vollmer WM. Using an asthma control questionnaire and administrative data to predict health-care utilization. Chest 2006 Apr;129(4):918-924. [doi: 10.1378/chest.129.4.918] [Medline: 16608939]

16. Yurk RA, Diette GB, Skinner EA, Dominici F, Clark RD, Steinwachs DM, et al. Predicting patient-reported asthma outcomes for adults in managed care. Am J Manag Care 2004 May;10(5):321-328 [FREE Full text] [Medline: 15152702]

17. Loymans RJ, Debray TP, Honkoop PJ, Termeer EH, Snoeck-Stroband JB, Schermer TR, et al. Exacerbations in adults with asthma: a systematic review and external validation of prediction models. J Allergy Clin Immunol Pract 2018;6(6):1942-1952. [doi: 10.1016/j.jaip.2018.02.004] [Medline: 29454163]

18. Lieu TA, Capra AM, Quesenberry CP, Mendoza GR, Mazar M. Computer-based models to identify high-risk adults with asthma: is the glass half empty of half full? J Asthma 1999 Jun;36(4):359-370. [doi: 10.3109/02770909909068229] [Medline: $\underline{10386500]}$ 
19. Schatz M, Nakahiro R, Jones CH, Roth RM, Joshua A, Petitti D. Asthma population management: development and validation of a practical 3-level risk stratification scheme. Am J Manag Care 2004 Jan;10(1):25-32 [FREE Full text] [Medline: 14738184]

20. Grana J, Preston S, McDermott PD, Hanchak NA. The use of administrative data to risk-stratify asthmatic patients. Am J Med Qual 1997;12(2):113-119. [doi: 10.1177/0885713X9701200205] [Medline: 9161058]

21. Forno E, Fuhlbrigge A, Soto-Quirós ME, Avila L, Raby BA, Brehm J, et al. Risk factors and predictive clinical scores for asthma exacerbations in childhood. Chest 2010 Nov;138(5):1156-1165 [FREE Full text] [doi: 10.1378/chest.09-2426] [Medline: 20472862]

22. Xiang Y, Ji H, Zhou Y, Li F, Du J, Rasmy L, et al. Asthma exacerbation prediction and risk factor analysis based on a time-sensitive, attentive neural network: retrospective cohort study. J Med Internet Res 2020 Jul 31;22(7):e16981 [FREE Full text] [doi: 10.2196/16981] [Medline: $\underline{32735224]}$

23. Luo G, He S, Stone BL, Nkoy FL, Johnson MD. Developing a model to predict hospital encounters for asthma in asthmatic patients: secondary analysis. JMIR Med Inform 2020 Jan 21;8(1):e16080 [FREE Full text] [doi: 10.2196/16080] [Medline: $\underline{31961332]}$

24. Mayfield J, McNamee P, Piatko CD. Named entity recognition using hundreds of thousands of features. In: Proceedings of the Seventh Conference on Natural Language Learning at HLT-NAACL 2003 - Volume 4. 2003 Presented at: CoNLL'03; May 31-June 1, 2003; Edmonton, Canada p. 184-187. [doi: 10.3115/1119176.1119205]

25. Cao Y, Yu H, Abbott NL, Zavala VM. Machine learning algorithms for liquid crystal-based sensors. ACS Sens 2018 Nov 26;3(11):2237-2245. [doi: 10.1021/acssensors.8b00100] [Medline: 30289249]

26. Zhai Y, Ong Y, Tsang IW. The emerging "Big Dimensionality". IEEE Comput Intell Mag 2014 Aug;9(3):14-26. [doi: 10.1109/mci.2014.2326099]

27. Hansson K, Yella S, Dougherty M, Fleyeh H. Machine learning algorithms in heavy process manufacturing. Am J Intell Syst 2016;6(1):1-13. [doi: 10.5923/j.ajis.20160601.01]

28. Liu LL, Forgione DA, Younis MZ. A comparative analysis of the CVP structure of nonprofit teaching and for-profit non-teaching hospitals. J Health Care Finance 2012;39(1):12-38. [Medline: 23155742]

29. Desai JR, Wu P, Nichols GA, Lieu TA, O'Connor PJ. Diabetes and asthma case identification, validation, and representativeness when using electronic health data to construct registries for comparative effectiveness and epidemiologic research. Med Care 2012 Jul;50 Suppl:30-35 [FREE Full text] [doi: 10.1097/MLR.0b013e318259c011] [Medline: 22692256]

30. Wakefield DB, Cloutier MM. Modifications to HEDIS and CSTE algorithms improve case recognition of pediatric asthma. Pediatr Pulmonol 2006 Oct;41(10):962-971. [doi: 10.1002/ppul.20476] [Medline: 16871628]

31. Steyerberg EW. Clinical Prediction Models: a Practical Approach to Development, Validation, and Updating, 2nd Ed. New York, NY: Springer; 2019.

32. Witten IH, Frank E, Hall MA, Pal CJ. Data Mining: Practical Machine Learning Tools and Techniques, 4th Ed. Burlington, MA: Morgan Kaufmann; 2016.

33. Chen T, Guestrin C. XGBoost: a scalable tree boosting system. In: Proceedings of the ACM SIGKDD International Conference on Knowledge Discovery and Data Mining. 2016 Presented at: KDD '16: 22nd ACM SIGKDD International Conference on Knowledge Discovery and Data Mining; August 13-17, 2016; San Francisco, CA p. 785-794. [doi: 10.1145/2939672.2939785]

34. XGBoost JVM Package. 2020. URL: https://xgboost.readthedocs.io/en/latest/jvm/index.html [accessed 2021-03-26]

35. Zeng X, Luo G. Progressive sampling-based Bayesian optimization for efficient and automatic machine learning model selection. Health Inf Sci Syst 2017 Dec;5(1):2 [FREE Full text] [doi: 10.1007/s13755-017-0023-z] [Medline: 29038732]

36. Thornton C, Hutter F, Hoos HH, Leyton-Brown K. Auto-WEKA: combined selection and hyperparameter optimization of classification algorithms. In: Proceedings of the ACM SIGKDD International Conference on Knowledge Discovery and Data Mining. 2013 Presented at: KDD'13: 19th ACM SIGKDD international conference on Knowledge discovery and data mining; August 11-14, 2013; Chicago Illinois USA p. 847-855. [doi: 10.1145/2487575.2487629]

37. Agresti A. Categorical Data Analysis, 3rd ed. Hoboken, NJ: Wiley; 2012.

38. Hastie T, Tibshirani R, Friedman J. The Elements of Statistical Learning: Data Mining, Inference, and Prediction, 2nd ed. New York, NY: Springer; 2016.

39. Luo G. Automatically explaining machine learning prediction results: a demonstration on type 2 diabetes risk prediction. Health Inf Sci Syst 2016;4:2 [FREE Full text] [doi: 10.1186/s13755-016-0015-4] [Medline: 26958341]

40. Luo G. A roadmap for semi-automatically extracting predictive and clinically meaningful temporal features from medical data for predictive modeling. Glob Transit 2019;1:61-82 [FREE Full text] [doi: 10.1016/j.glt.2018.11.001] [Medline: $\underline{31032483}$ ]

41. Ranganathan P, Aggarwal R. Common pitfalls in statistical analysis: understanding the properties of diagnostic tests - Part 1. Perspect Clin Res 2018;9(1):40-43. [doi: 10.4103/picr.picr_170_17]

42. Kuhn M, Johnson K. Applied Predictive Modeling. New York, NY: Springer; 2013.

43. Asadi H, Dowling R, Yan B, Mitchell P. Machine learning for outcome prediction of acute ischemic stroke post intra-arterial therapy. PLoS One 2014;9(2):e88225 [FREE Full text] [doi: 10.1371/journal.pone.0088225] [Medline: 24520356] 
44. Luo G, Nau CL, Crawford WW, Schatz M, Zeiger RS, Rozema E, et al. Developing a predictive model for asthma-related hospital encounters in patients with asthma in a large, integrated health care system: secondary analysis. JMIR Med Inform 2020 Nov 09;8(11):e22689 [FREE Full text] [doi: 10.2196/22689] [Medline: $\underline{33164906}$ ]

45. XGBoost Parameters. 2020. URL: https://xgboost.readthedocs.io/en/latest/parameter.html [accessed 2021-03-26]

46. Notes on Parameter Tuning. 2020. URL: https://xgboost.readthedocs.io/en/latest/tutorials/param tuning.html [accessed 2021-03-26]

47. Luo G, Stone BL, Koebnick C, He S, Au DH, Sheng X, et al. Using temporal features to provide data-driven clinical early warnings for chronic obstructive pulmonary disease and asthma care management: protocol for a secondary analysis. JMIR Res Protoc 2019 Jun 06;8(6):e13783 [FREE Full text] [doi: 10.2196/13783] [Medline: $\underline{31199308]}$

48. Bourgeois FC, Olson KL, Mandl KD. Patients treated at multiple acute health care facilities: quantifying information fragmentation. Arch Intern Med 2010 Dec 13;170(22):1989-1995. [doi: 10.1001/archinternmed.2010.439] [Medline: 21149756]

49. Finnell JT, Overhage JM, Grannis S. All health care is not local: an evaluation of the distribution of emergency department care delivered in Indiana. AMIA Annu Symp Proc 2011;2011:409-416 [FREE Full text] [Medline: 22195094]

50. Luo G, Tarczy-Hornoch P, Wilcox AB, Lee ES. Identifying patients who are likely to receive most of their care from a specific health care system: demonstration via secondary analysis. JMIR Med Inform 2018 Nov 05;6(4):e12241 [FREE Full text] [doi: 10.2196/12241] [Medline: 30401670]

51. Kern LM, Grinspan Z, Shapiro JS, Kaushal R. Patients' use of multiple hospitals in a major US city: implications for population management. Popul Health Manag 2017 Apr;20(2):99-102 [FREE Full text] [doi: 10.1089/pop.2016.0021] [Medline: 27268133]

52. Samuels-Kalow ME, Faridi MK, Espinola JA, Klig JE, Camargo CAJ. Comparing statewide and single-center data to predict high-frequency emergency department utilization among patients with asthma exacerbation. Acad Emerg Med 2018 Jun;25(6):657-667 [FREE Full text] [doi: 10.1111/acem.13342] [Medline: 29105238]

\author{
Abbreviations \\ AUC: area under the receiver operating characteristic curve \\ ED: emergency department \\ FN: false negative \\ FP: false positive \\ ICD-10: International Classification of Diseases, Tenth Revision \\ ICD-9: International Classification of Diseases, Ninth Revision \\ NPV: negative predictive value \\ PCP: primary care provider \\ PPV: positive predictive value \\ TN: true negative \\ TP: true positive \\ UWM: University of Washington Medicine \\ Weka: Waikato Environment for Knowledge Analysis \\ XGBoost: extreme gradient boosting
}

Edited by R Kukafka; submitted 26.08.20; peer-reviewed by Y Xiang, J Fonseca; comments to author 20.10.20; revised version received
31.10.20; accepted 22.03.21; published 16.04.21
Please cite as:
Tong Y, Messinger AI, Wilcox AB, Mooney SD, Davidson GH, Suri P, Luo G
Forecasting Future Asthma Hospital Encounters of Patients With Asthma in an Academic Health Care System: Predictive Model
Development and Secondary Analysis Study
J Med Internet Res 2021;23(4):e22796
URL: https://www.jmir.org/2021/4/e22796
doi: $10.2196 / 22796$
PMID:

(C) Yao Tong, Amanda I Messinger, Adam B Wilcox, Sean D Mooney, Giana H Davidson, Pradeep Suri, Gang Luo. Originally published in the Journal of Medical Internet Research (http://www.jmir.org), 16.04.2021. This is an open-access article distributed under the terms of the Creative Commons Attribution License (https://creativecommons.org/licenses/by/4.0/), which permits unrestricted use, distribution, and reproduction in any medium, provided the original work, first published in the Journal of 
Medical Internet Research, is properly cited. The complete bibliographic information, a link to the original publication on http://www.jmir.org/, as well as this copyright and license information must be included. 